\title{
Transformational Leadership Educational Program for Head Nurses and its Effect on Nurses' Job Performance
}

\author{
Ebtesam Saeed Ahmed Abd-EIrhaman, Nora Ahmed Abd-Allah \\ Nursing Administration Department, Faculty of Nursing, Benha University, Banha, Egypt \\ Email address: \\ noura.mohamed@fnur.bu.edu.eg(N.A.Abd-Allah),Foreversmilely@yahoo.com(E. S. A. Abd-Elrhaman)
}

To cite this article:

Ebtesam Saeed Ahmed Abd-Elrhaman, Nora Ahmed Abd-Allah. Transformational Leadership Educational Program for Head Nurses and its Effect on Nurses' Job Performance. American Journal of Nursing Science. Vol. 7, No. 4, 2018, pp. 127-136.

doi: $10.11648 /$ j.ajns.20180704.13

Received: April 29, 2018; Accepted: May 28, 2018; Published: June 15, 2018

\begin{abstract}
Head nurses` who apply transformational leadership find innovative approaches that enhance staff nurses` performance at their highest level to achieve a vision of quality health care. Also, transformational leader has a major impact on the staff nurses' behavior to achieve health care organization goals as, this leader setting new direction, inspiration, and behaviors for their health care organization. Aim: to assess the transformational leadership educational program for head nurses and its effect on nurses' job performance. Research design: A quasi experimental design. Setting: The study was conducted in all units at Benha University Hospital. Sample: all the available head nurses and their assistants (103) and the convenient staff nurses (138) from the above mentioned setting. Tools: Three tools were used: (1) transformational leadership knowledge questionnaire, (2) the multifactor leadership questionnaire Form 5X Short (MLQ leader form), and (3) nurses' job performance evaluation (Observation Checklist). Results and Conclusion: showed that there was highly statistically significant improvement in head nurses' knowledge scores and skills regarding transformational leadership immediate post program and three months follow up the program than pre program scores. Also, there was highly statistically significant improvement in scores of job performance elements among staff nurses immediate post program and three months follow up the program than pre program scores as observed by the researcher. Recommendations: Conduct continuous in-service training and education programs for refreshing and increasing head nurses' knowledge and skills about the transformational leadership style.
\end{abstract}

Keywords: Head Nurses, Leadership, Transformational, MLQ, Staff Nurses Performance

\section{Introduction}

Within the fast changing in health care environment, certainly calls for nursing leaders with the ability to craft a transforming vision and effectively express it. One of the most important roles that contribute to leadership effectiveness is the style of the leader. A leadership style is the behavior a leader exhibits while guiding staff in a suitable directions $[4,50]$. Transformational leaders are an integral part of organizations today and those leaders focus on building relationships with followers and creating change by emphasizing values. Moreover it is intended to motivate and inspire followers to pursue goals and even exceeded. Also, Transformational leaders develop followers by providing them with further responsibilities, and by having the confidence in them to fulfill these duties with self-assurance and inspiration [53].
In other words, this style has been highly regarded as the key elements, and most critical factor to transcend organizations and individuals through shaping a shared vision [49]. Additionally, transformational Leadership defined as the style where one or more persons engage with others in such a way that leaders and followers raise one another to higher levels of motivation and morality. So, it is transforming nursing work environments that lead to high level work performance for staff nurses' [40].

Nursing transformational leadership has become a predominant leadership style practiced by nurse managers in healthcare organizations. The American Organization of Nurse Executives; considers transformational leadership "the preferred" leadership style for nursing leaders, this preference is supported by the perspective that transformational nurse leaders are "the key to strengthening health-systems worldwide" [22]. Transformational leadership styles appear to be more suitable for 
application in nursing [43] Also, it is very important aspects of leadership that are highly associated with individual as well as organizational performance [3].

Additionally, behavioral components determine the ability of transformational leaders to inspire their followers were characterized as; idealized influence (attributes) (IA), idealized influence (behaviors) (IB), inspirational motivation (IM), intellectual stimulation (IS), and individual consideration (IC) [8, 23, 25, 51]. First; idealized influence; included idealized attributes (IA) and idealized behavior (IB) as an aspect of transformational leadership. Idealized attributes are the attributes in which the followers are proud to be associated with the leader. The leader is confident, respected and put the groups needs over self. Idealized behaviors exhibited by the leader emphasize the follower's beliefs. As a role model, the transformational leader exhibits high moral standards and, ethical behavior $[6,33]$.

Second, inspirational motivation; the Leaders engage, motivate, and persuade followers to envision and work toward "attractive future states". Also, transformational leaders sell themselves and their vision by demonstrating a sincere and passionate commitment to that vision, goals, and people within the organization as well as clearly communicating expectations [19, 23]. Intellectual stimulation is the third one, which means a leader encourages followers' within the organization to question and challenge assumptions, and to look at old problems in new ways. The leader is willing to take risks and abandon inefficient systems, including those that are long standing practices within an organization $[6,10]$.

Individualized consideration is the fourth and final factor of transformational leadership. Those leaders emphasis on growth and achievement. A variety of skills including; coaching, mentoring, listening, advising, empathy, encouragement, and feedback are used to create a supportive environment for success [32], such an environment empowers followers to achieve their full potential enabling them to complete work more successfully, leading to positive self-esteem and increased self-efficacy [47]. The transformational leadership concepts which emphasize the role of the follower (staff nurses) as well as the leader, have the potential to increase performance throughout an organization [12]. Adopting transformational leadership behavior helps in the success of the organization [26]. So, head nurses who have this style act as role models for their staff nurses. They seek new and nontraditional methods of working, such head nurses encourage their staff nurses to think differently, seek new chances, and find new solutions to solve problems beyond themselves and become high performers $[14,18]$.

Work performance in nurses can be viewed as the effectiveness of the nurse in carrying out their roles and responsibilities related to direct patient care. Four elements to assess job performance of staff nurses, first expected hospital behavior including; courtesy, respect, communication, comfort, responsiveness, team work, and professionalism. Second, nursing process including; assessment, diagnosis, implementation, evaluation, and documentation. Third, quality of care and, fourth education [15].Also, staff nurses' performance was described as the formal exhibition of a skill, and ability. Performance evaluation in nursing is concerned with measuring the efficiency, effectiveness and competency of the nursing process and activities used by staff nurses in the care of clients by their head nurses` [52].

Therefore, Head nurses' play an important role in success of health care setting as they are interact with most staff nurses ' on a daily basis and have a very strong impact on them. Training first-line managers has become an obligatory task that organizations must pay more attention to it today $[11,31]$. Successful leadership training programs in nursing are multidimensional and purposefully individualized. They include didactic work as well as components that are interactive and experiential [37, 54].

\subsection{Significance of the Study}

Head nurses' practiced transformational leadership empowers the staff nurses to build the good relationship and to meet the organizational goals and, match staff nurses' interests and abilities to their job functions so, added meaning to the work of staff nurses all of this lead to high staff nurses' performance. In addition, transformational leadership style has been widely adopted in the nursing profession and results into positive clinical outcomes. Moreover, transformational leadership enhance the staff nurse's self-esteem and motivates them to give their best. Recently, inspection of the nursing field reveals the lack of preparation and knowledge regarding qualities of a transformational leader [44, 53]. However, developing and implementing this leadership style is challenging because undoubtedly plays a strategic tool to motivate the staff nurses to enhance their potential growth and development $[35,52]$. Nowadays the key challenge for the modern organization is to recognize the effects of strong leadership on the nursing performance and the success of the organization. So, improving head nurses' transformational leadership will lead to improvements in staff nurses` job performance.

\subsection{Aim of the Study}

This study was aimed to assess the transformational leadership educational program for head nurses and its effect on nurses' job performance.

\subsection{Research Hypothesis}

1. There will be significant improvement of head nurses' knowledge, skills related to transformational leadership after implementation of educational program.

2. Nurses' job performance will be greatly improved after implementation of educational program for head nurses` than before.

3. There will be a positive correlation between head nurses' transformational leadership and nurses' job performance after implementation of educational program. 


\section{Subjects and Methods}

\subsection{Research Design}

A quasi- experimental research design was utilized to conduct the study with pre/post test.

\subsection{Setting}

The study was conducted in all units (57) at Benha University Hospital.

\subsection{Subjects}

\subsubsection{Subject Type}

A convenient sample

\subsubsection{Subject Size}

All the available head nurses and their assistants (103), and all the convenient staff nurses (138) who are working in the above mention study setting, at the time of study and agree to participate after clarification of purpose of the study.

\subsection{Tools of Data Collection}

Three tools were used by the researchers.

\subsubsection{Transformational Leadership Knowledge Questionnaire}

A structured questionnaire developed by the researchers based on the review of the related literature [6, 33, 40]. To assess the head nurses transformational leadership knowledge. It had two main parts: Part I: It consisted of items related to personal characteristics of the study subjects such as (age, sex, department, qualification, years of experience, marital status, and previous training in leadership). Part II: It consisted of 20 questions (true and false " 8 " questions and, multiple choice "12" questions).

Scoring system:

The questions were scored as "1" for correct answer, and "zero" for incorrect answer. The total scores were summed up and transformational leadership knowledge expressed as follow; more than $60 \%$ was considered had adequate knowledge, and less than $60 \%$ was considered had inadequate knowledge.

\subsubsection{The Multifactor Leadership Questionnaire $5 X$ Rater Form: (MLQ $5 X$ Leader Form)}

It includes 20-items scale adapted by [8], discussed only transformational leadership from the original 45 -item survey, measuring several leadership styles. It was used for assessing head nurses' transformational leadership behavior. It consists of five dimensions, namely (1) Idealized attribute (4 items), (2) Idealized behavior (4 items), (3) Inspirational motivation (4 items), (4) Intellectual stimulation (4 items), and finally (5) Individual consideration (4 items).

Scoring system:

There was a five point Likert- scale ranging from (0-4) not at all (0), once in a while (1), sometimes (2), fairly often (3) and frequently if not always (4). The score for each dimension in the MLQ form is determined by summing four specified items on the questionnaire.

\subsubsection{Nurses'Job Performance Evaluation (Observation Checklist)}

This tool was initially developed by [15], and has since been used to assess job performance of staff nurses. It had two main parts: Part I: It consisted of items related to personal characteristics of the staff nurses such as (age, sex, department, qualification, years of experience, and marital status).

Part II: It consists of four elements, namely (1) expected hospital behavior [including courtesy (four items); respect (four items); communication (three items); comfort (one item); responsiveness (two items); team work (six items); and professionalism (composed of five items]; (2) nursing process [including assessment (three items), diagnosis (two items), implementation (six items), evaluation (two items), and documentation (composed of five items]; (3) quality of care (three items); and (4) education (four items).

Scoring System.

The responses pertaining to performance elements were, given on a three-point Likert scale, comprising the following options: 3 = Competent, $2=$ Needs improvement, and $1=$ Unacceptable. The nurse performance was considered competent if her composite score on this scale exceeded $68 \%$, and incompetent otherwise [21].

\subsection{Methods}

The study was executed according to the following steps

\subsubsection{Tools Validity and Reliability}

The tools were reviewed by expert panel of different nursing departments. The panel ascertained the face and content validity of the tools. The reliability was done by Cronbach's Alpha coefficient test. Cronbach's alphas were $(\mathrm{r}=0.92,0.89 \& 0.96)$ transformational leadership knowledge questionnaire, the multifactor leadership questionnaire, nurses' job performance evaluation respectively.

\subsubsection{Ethical Considerations}

Each head nurse and assistant, and staff nurse were informed about the purpose and benefits of the study then oral consent was obtained before starting the data collection. Confidentiality was ensured throughout the study. The head nurses and staff nurses were assured that all data was used only for research purpose and each head nurses and staff nurses were informed of the rights to refuse or withdraw at any time of the study.

\subsubsection{The Pilot Study}

A pilot study was carried out on $10 \%$ from the total number of sample (10) head nurses and (13) staff nurses to assess the tools clarity, objectivity and feasibility as well as to estimate the time needed for filling the tools. No modifications were done. The pilot study was included in the main study sample. 


\subsubsection{Educational Program}

Transformational leadership program was designed to provide head nurses an opportunity to develop transformational leadership knowledge and skill. It covering the following items; definition, components, factors, qualities, goal, advantages \&disadvantage, theories, weakness \& strength, impact, challenges, and application.

\subsubsection{Field Work}

A written official letter was obtained from the dean of the Faculty of Nursing, Benha University and delivered to the director of Benha University Hospital in order to obtain their approval for conducting the study after explaining its purpose. The study was carried out from at the beginning of September 2016 to the end of June 2017.

The head nurses and their assistants are grouped according their department location into 8 groups; each group contains 13 except only one group contains 12 head nurses. The preprogram conduct at September 2016. The transformational leadership knowledge questionnaire sheet (pre test) was fulfilled by the subjects before beginning of the training program. The transformational leadership knowledge questionnaire sheet took from 30-40 minutes to be completed, and 15-20 minute for completing MLQ. This prestudy test was designed to allow the researchers collect a baseline assessment of head nurses' knowledge and skills in order to compare it with immediate post and follow-up program. The data collected two days/week in the morning and afternoon shift.

After the questionnaires were completed, the training program was implemented by the researchers. The time plan of the program implemented over the period from October 2016 to November 2016. The training program has taken 16 hours distributed as the following; 8 sessions, 2hour/session, 2days/week. Each researcher implements the program with one group in the days by using available resources, relevant contents and instructional strategies for each session. Different methods of teaching were used such as lectures, group discussion, and brainstorming. Instructional media included handout prepared by the researchers and distributed to all participants in the first day of the program.

During the period of December 2016 to January 2017 the immediate effect (post test1) of the in-service education program was evaluated by using the same previous mentioned tools. Follow -up (post test2): This evaluation was done after three months this phase took a period of two months from May 2017 to June 2017. During this phase, the impact of the in-service education program was evaluated, using the same tools which were used before the program.

In relation to job performance, an observational method was utilized to determine staff nurses performance level. Researcher observed every nurse three times to ensure their level of performance, with data being collected 2 days/week over two shifts. The data were collected over 10 months, from the beginning of September 2016 to the end of June 2017.

\subsubsection{Statistical Analysis}

Data were collected, entered and analyzed by using SPSS (version 20) software computer package (special package for social science). Presented in tabular form. Descriptive statistics were applied (e.g., frequency, percentages, mean, and standard deviation). Test of significance Chi-square "X2", paired t-test and correlation coefficient (r) were used. A statistically significant difference was considered at $\mathrm{p}$-value $\mathrm{p} \leq 0.05$.

\section{Results}

Table 1: Showed that the total number of head nurses was 103 , staff nurses were 138 and the majority of both of them were female, married, working at medical departments. In relation to their qualification; $(56.2 \%)$ of head nurses had bachelor degree and (42.8\%) of staff nurses had diploma degree in nursing. As far as their age more than half of both of them were aged 26-35 years. Regarding to their years of experience $(44.7 \%)$ of head nurses had $15-30$ years of experience while $(40.5 \%)$ of staff nurses had 5-15 years of experience. And (93.2\%) of head nurses didn't having training in leadership.

Figure 1: Illustrated that there was highly statistically significant improvement in head nurses' knowledge scores regarding transformational leadership immediate post program and three months follow up the program than pre program scores.

Table 2: Clarified that there was statistically significant improvement of mean and standard deviation of transformational leadership style which include the dimensions of " idealized attribute, idealized behavior, inspirational motivation, intellectual stimulation, and finally individual consideration " immediate post program and three months follow up the program than pre program scores as reported by head nurses.

Table 3: Displayed that there was highly statistically significant improvement in scores of job performance elements which include "expected hospital behavioral, nursing process, quality of care, education process" among staff nurses immediate post program and three months follow up the program than pre program scores as observed by the researcher.

Table 4: Showed that there was positive statistical significant correlation between staff nurses' total job performance score pre program and head nurses' total transformational leadership style Pre, immediately post and follow up program. Also, this table found that there was positive statistical significant correlation between staff nurses` total job performance score post program and head nurses` total transformational leadership style pre and follow up program. Finally, the table demonstrated that there was positive statistical significant correlation between staff nurses` total job performance score follow up program and head nurses' total transformational leadership style pre, immediately post and follow up program.

Table 5: Findings of the table displayed that there was 
positive statistical significant correlation between years of experience and, educational level for head nurses transformational leadership style and staff nurses' job

performance, and there is negative correlation between age and staff nurses job performance.

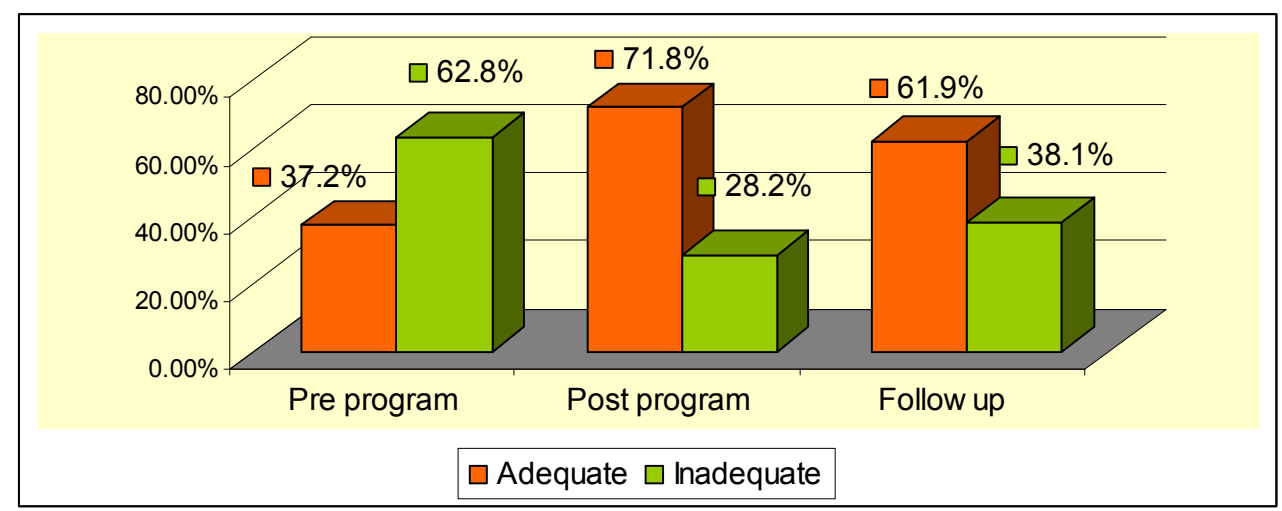

Figure 1. Level of head nurses knowledge about transformational leadership thorough program $(n=103)$.

Table 1. Personal characteristics of studied participants.

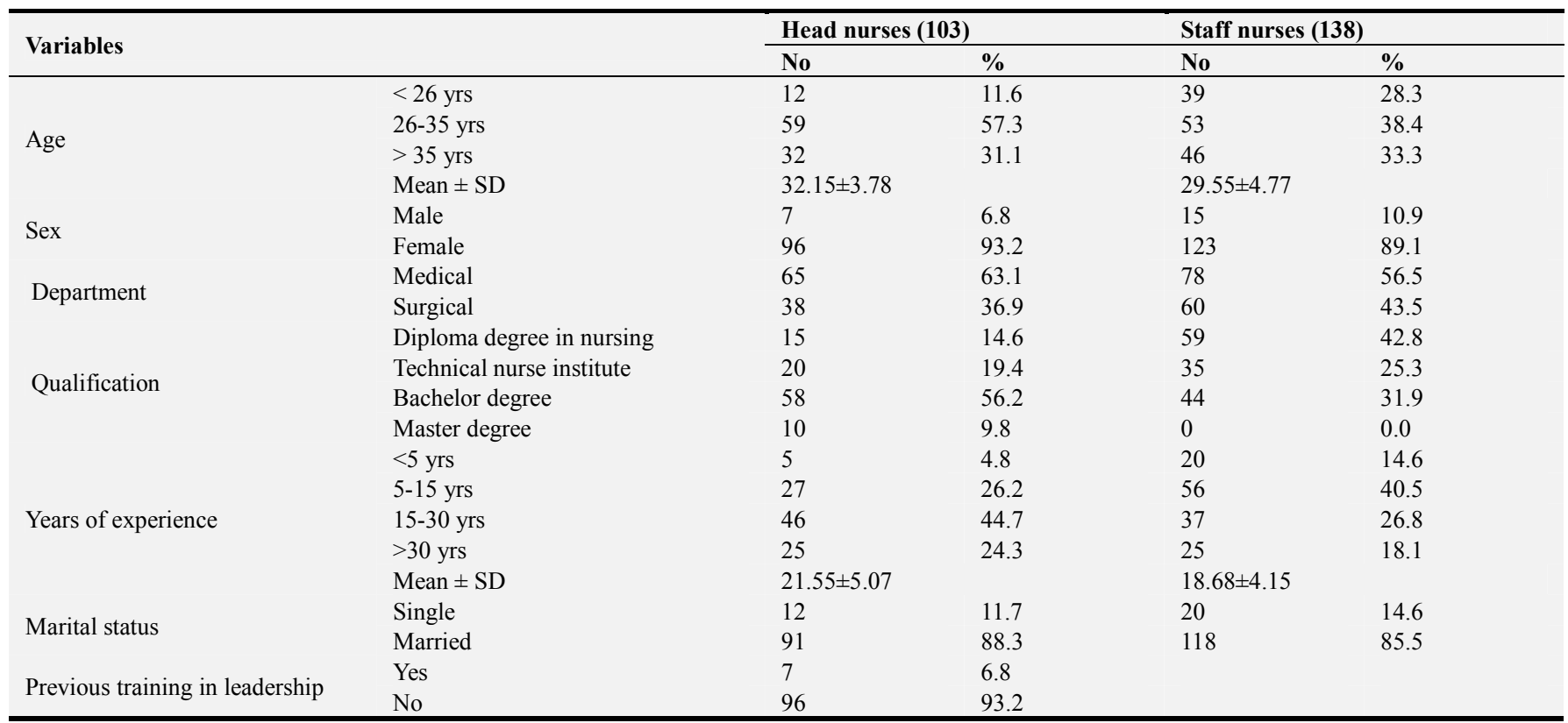

Table 2. Mean and standard deviation of transformational leadership among head nurses thorough program ( $n=103)$.

\begin{tabular}{|c|c|c|c|c|c|c|c|}
\hline Transformational leadership & $\begin{array}{l}\text { Pre program } \\
\text { Mean } \pm \text { SD }\end{array}$ & $\begin{array}{l}\text { Post program Mean } \\
\pm \text { SD }\end{array}$ & $\begin{array}{l}\text { Follow up program } \\
\text { Mean } \pm \text { SD }\end{array}$ & t-test 1 & $P$ value & t-test 2 & $P$ value \\
\hline Idealized attribute & $4.54 \pm 1.55$ & $14.23 \pm 1.13$ & $10.75 \pm 1.01$ & 64.619 & $0.000 * *$ & 38.000 & $0.000 * *$ \\
\hline Idealized behavior & $5.38 \pm 1.33$ & $15.39 \pm 0.53$ & $11.59 \pm 1.53$ & 78.579 & $0.000 * *$ & 40.536 & $0.000 * *$ \\
\hline Inspirational Motivation & $4.64 \pm 1.25$ & $14.13 \pm 1.01$ & $11.84 \pm 1.27$ & 57.366 & $0.000 * *$ & 39.383 & $0.000 * *$ \\
\hline Intellectual Stimulation & $4.61 \pm 1.19$ & $12.94 \pm 1.19$ & $10.91 \pm 1.07$ & 82.039 & $0.000 * *$ & 47.071 & $0.000 * *$ \\
\hline Individualized Consideration & $4.04 \pm 1.46$ & $14.13 \pm 0.96$ & $10.70 \pm 1.41$ & 66.588 & $0.000 * *$ & 38.149 & $0.000 * *$ \\
\hline Total & $23.23 \pm 3.10$ & $70.95 \pm 2.31$ & $55.81 \pm 3.26$ & 151.745 & $0.000 * *$ & 83.213 & $0.000 * *$ \\
\hline
\end{tabular}

A highly statistical significant difference $(\mathrm{P} \leq 0.001)$

t-test 1: pre \& post

t-test 2: pre \& follow up

Table 3. Mean and standard deviation of job performance among staff nurses thorough program $(n=138)$.

\begin{tabular}{|c|c|c|c|c|c|c|c|}
\hline Job Performance Elements & $\begin{array}{l}\text { Pre program } \\
\text { Mean } \pm \text { SD }\end{array}$ & $\begin{array}{l}\text { Post program } \\
\text { Mean } \pm \text { SD } \\
\end{array}$ & $\begin{array}{l}\text { Follow up program } \\
\text { Mean } \pm \text { SD }\end{array}$ & t-test 1 & $P$ value & t-test 2 & P value \\
\hline 1-Hospital Behavior Expectation & $33.87 \pm 3.06$ & $55.52 \pm 5.25$ & $48.29 \pm 6.16$ & 43.367 & $0.000 * *$ & 23.962 & $0.000 * *$ \\
\hline 2- Nursing process & $28.42 \pm 5.95$ & $36.188 \pm 5.76$ & $32.47 \pm 5.12$ & 11.723 & $0.000 * *$ & 5.347 & $0.000 * *$ \\
\hline
\end{tabular}




\begin{tabular}{llllllll}
\hline \multirow{2}{*}{ Job Performance Elements } & $\begin{array}{l}\text { Pre program } \\
\text { Mean } \pm \text { SD }\end{array}$ & $\begin{array}{l}\text { Post program } \\
\text { Mean } \pm \text { SD }\end{array}$ & $\begin{array}{l}\text { Follow up program } \\
\text { Mean } \pm \text { SD }\end{array}$ & t-test 1 & P value & t-test 2 & P value \\
\hline 3- Quality of care & $4.82 \pm 1.20$ & $5.80 \pm 1.61$ & $5.15 \pm 1.17$ & 6.162 & $0.000^{* *}$ & 2.195 & $0.000^{* *}$ \\
4- Education process & $4.50 \pm 1.06$ & $8.21 \pm 1.81$ & $6.95 \pm 1.66$ & 21.103 & $0.000^{* *}$ & 14.611 & $0.000^{* *}$ \\
Total job performance & $71.64 \pm 7.52$ & $105.98 \pm 9.03$ & $91.94 \pm 8.58$ & 37.886 & $0.000^{* *}$ & 20.359 & $0.000^{* *}$ \\
\hline
\end{tabular}

**A highly statistical significant difference $(\mathrm{P} \leq 0.001)$

t-test 1: pre \& post

t-test 2: pre \& follow up

Table 4. Correlation between head nurses` transformational leadership style and their staff nurses job performance.

\begin{tabular}{|c|c|c|c|c|c|c|}
\hline \multirow{3}{*}{$\begin{array}{l}\text { Transformational leadership among head } \\
\text { nurses }(n=103)\end{array}$} & \multicolumn{6}{|c|}{ Staff nurses Job performance $(n=138)$} \\
\hline & \multicolumn{2}{|c|}{$\begin{array}{l}\text { Total job performance score } \\
\text { Pre program }\end{array}$} & \multicolumn{2}{|c|}{$\begin{array}{l}\text { Total job performance score } \\
\text { Post program }\end{array}$} & \multicolumn{2}{|c|}{$\begin{array}{l}\text { Total job performance score } \\
\text { follow up program }\end{array}$} \\
\hline & $R$ & $P$ & $r$ & $P$ & $r$ & $p$ \\
\hline Total Transformational Pre program & 0.193 & $0.018 *$ & 0.131 & $0.018^{*}$ & 0.760 & $0.031 *$ \\
\hline Total Transformational Post program & 0.242 & $0.014 *$ & 0.135 & 0.174 & 0.435 & $0.038^{*}$ \\
\hline Total Transformational Follow up program & 0.956 & $0.005^{*}$ & 0.109 & $0.027 *$ & 0.076 & $0.045^{*}$ \\
\hline
\end{tabular}

* Statistically significant. $(\mathrm{p} \leq 0.05)$

$(\mathrm{r}) *$ correlation coefficient.

Table 5. Correlation between age, experience, educational level related to head nurses` transformational leadership style and their staff nurses` job performance.

\begin{tabular}{lllll}
\hline \multirow{2}{*}{ Personal characteristics } & \multicolumn{2}{l}{ Head nurses Transformational leadership style } & \multicolumn{2}{l}{ Staff Nurses' Job Performance } \\
\cline { 2 - 5 } & $\mathbf{r}$ & $\mathbf{P}$ & $\mathbf{P}$ & $\mathbf{P}$ \\
\hline Age & 0.075 & 0449 & -0.189 & $0.026^{*}$ \\
Years of experience & 0.305 & $0.002^{* *}$ & 0.214 & $0.012^{*}$ \\
Educational level & 0.217 & $0.028^{*}$ & 0.131 & $0.018^{*}$ \\
\hline
\end{tabular}

* Statistically significant. $(\mathrm{p} \leq 0.05)$

$(\mathrm{r}) *$ correlation coefficient.

\section{Discussion}

Transformational leadership is one of the various modern leadership styles; it is based on visionary leader by challenge worker to take greater ownership of their work, to do more than their performance beyond expectation to organization is needed. So, transformational leadership training program has been achieved for supporting head nurses to perform managerial roles effectively and, enhance their skills [49].

Regarding head nurses' transformational leadership knowledge, the result of the present study revealed that there was general improvement in head nurses' knowledge at immediate post program and three months follow-up program as compared to the preprogram. Also, there was highly statistically significant difference among study phase. This could be the ability of the head nurses to gain knowledge easily and they are interested in the research topics.

This result was parallel with [5], who conduct study about "impact of transformational leadership training program on nurse's unit manager behavior change "reported that total levels of nursing managers' knowledge and all items related to transformational leadership program were significantly improved post 1 and post 2 than pre-program.

Besides, this result is comparable to research by [38], who carried out study on "effect of nurse's supervisor's leadership style on nurse's job satisfaction" stated that the supervisors/heads of departments perceived that they used transformational leadership as a whole. [7], who performed study on "nursing leadership in the ministry of health hospitals of Saudi Arabia" initiated that nurse managers considered themselves to be more transformational. Further [1], deduced that the highest score was seen to be with the head nurses who followed the transformational style of leadership. On other side result by [48], indicated that the majority of the North Gondar Zone public preparatory school teachers' level of overall transformational leadership is low.

In particular, the current results clarified that there was statistically significant improvement of mean and standard deviation of transformational leadership style which include the dimensions of "Idealized attribute, Idealized behavior, Inspirational motivation, Intellectual stimulation, and finally Individual consideration " immediate post program and three months follow up the program than pre program scores as reported by head nurses. This finding may be due to the head nurses had understand their basic transformational leader role, that will enable them to perform their tasks effectively and efficiently. Along with the present study results [16], who conducted study on "leadership styles and outcome patterns for the nursing workforce and work environment", concluded that when using the MLQ questionnaire, reported significant increases in leader behavior score after sharing in the transformational leadership development program.

As well, the result of the present study revealed that the highest items mean scores for five dimensions of transformational leadership are inspiration motivation and idealized behavioral influence respectively, this might be due to most of head nurses in Benha University Hospital have 
enough information and ability to motivate and transfer hope and goal to their staff nurses and, head nurses are leaders who fairly often talk about important values in organization and focus on attractive and worthwhile visions and the ethical aspects of their activities as values are very important for them. Further they behave in ways that optimize a strong sense of purpose and talk about their most important values and belief. Head nurses act in ways that foster respect and provide a strong role model to follow.

This result was supported with [45]. In addition to, this result is similar to research by [38], who found that the supervisors/heads of departments perceived that they used idealized influence domain. And [7], found that managers valued idealized influence more highly. Also, [41], conduct study on transformational leadership and its predictive effects on leadership effectiveness", found that idealized influence dimension of transformational leadership received the highest mean scores.

On the contrary, [17] disagreed with the present finding who conduct study on "the effects of transformational leadership personality on employee performance in Nissan Malang mediated by organizational commitment" declared that inspiration motivation and individualized consideration have lower value than other indicators. Furthermore, [3], who conduct study on "impact of transformational leadership on employee motivation in telecommunication sector " listed that individualized consideration" having low score as compared to other dimensions of transformational leadership.

Concerning, staff nurses job performance elements the result of present study indicated that highly statistically significant improvement in scores of job performance elements among staff nurses. Also, the highest score for nursing process, and quality of care respectively. These findings interpret that there was continuous training, inservice education, presence of follow up, and give feedback for nurses' performance from their transformational head nurses for upgrading their behavior and improving areas of nursing process that reflect quality of patient care. In the same line, [42] who done study about " the role of leadership practices on job stress among Malay academic staff, structural equation modeling analysis "asserted that when the leader creates a positive climate and provides support to followers they devote their greatest efforts to the task and achieve the best work results.

This result matched with [24], done research on "ethical leadership, professional caregivers' well-being, and patients' perceptions of quality of care in oncology" found leader influence the quality of care of their followers, especially in the oncology setting. Similarly, agreed with [29], who performed study on " transformational and abusive leadership practices: impacts on novice nurses, quality of care and intention to leave" emphasized that transformational leadership practices are key variables associated with quality of care among nurses. The same line with [13], in their study of "transformational leadership and social identity as predictors of team climate, perceived quality of care, burnout and turnover intention among nurses". These results contradicted with [9], in their study of factors affecting the performance of professional nurses in Namibia. They found that lack of performance appraisal negatively affect employee performance.

Furthermore, there was a positive statistically significant correlation between transformational, leadership style and their staff nurses' job performance. This might be due to the program was positively affecting head nurses behavior to help, support, inspire, and motivate their staff nurses to overcome obstacles in daily basis in order to achieve their job performance. The finding of the present study are consistent with [45], who accomplish study on " the relationship between transformational leadership and employees" satisfaction at Jordanian private hospitals" mention that a statistically significant positive relationship existing between the five dimensions of transformational leadership following participation in development program and proved that high productivity, a decrease in the rate of job leaving, and high levels of job performance.

Additionally, this result was supported with [36], who done study on " transformational and transactional leadership and followers' achievement goals" revealed that transformational leadership was positively related to followers' endorsement of mastery goals, or (performance goal). And, in this respect [34], who conduct study on "evaluation of a clinical leadership program for nurse leaders" emphasized that transformational leadership could lead to higher followers' performance in the organizations. Also, this result matched with [46], who performed study about "transformational leadership and employee creativity" point out that transformational leadership had a greater role to play regarding followers' performance and creativity.

In the same line with, [30] who conducts study about "transformational leadership and safety performance among nurses" stated that transformational head nurses are able to influence their nurses' lead to increases in both dimensions of nurses' safety performance. Also, [23] concluded that transformational leader is associated with high performing teams and improved patient care.

In the similar spirit the study, [41] who conduct study about "transformational leadership and its predictive effects on leadership effectiveness" found that managers who display transformational leadership behavior were realized to be more effective leaders with better work outcomes. Also, consistent with [39], highlighted the positive contribution of leadership to favorable outcomes such as performance.

On the contrary, [17] disagreed with the present finding indicated that transformational leadership has no significant effects on employee performance. Also, On opposite, [27] who conduct study on "the influence of nurse manager transformational leadership on nurse and patient outcomes" found that nurses' perceptions of their managers' transformational leadership behaviors had negative effects on objectively measured adverse events (i.e., patient falls and hospital infections) through supportive practice environments and organizational citizenship behaviors.

Additionally, the current study displayed that there was 
positive statistical significant correlation between years of experience and educational level for head nurses transformational leadership style and staff nurses' job performance, and there is negative correlation between age and staff nurses job performance. This might be due to highly educated and experienced staff can do certain tasks easily and efficiently compared to who are educated lesser. Also, staff nurses job performance decrease with age this might be due to lose interest in their work for having done for a long time and they feel sense of boredom in the work and there by perform lesser.

This result is supported by [20], who found that there are relationships between leadership style and number of years of experience. And, [33] conducted a survey involving a sample of 50 library deans using the Multifactor leadership questionnaire and reported a strong correlation between years of experience and behaviors consistent with transformational leadership. Additionally, matched [28], who performed study indicated that the performance of the employees gradually increases with their experience and after an experience of 20 years the performance is again getting lower.

\section{Conclusion}

Based on the findings of the current study; revealed that the educational program done by the researcher succeeded in improving the head nurses` and their assistants ' knowledge and skills about transformational leadership as compared to pre course knowledge and skills. And there was very highly statistically significant improvement in nurses' job performance post program as compared with pre program scores.

\section{Recommendations}

Based on the findings of the current study, the following recommendations can be suggested;

1. Conduct continuous in-service training and education programs for refreshing and increasing head nurses' knowledge and skills about the transformational leadership style.

2. Transformational leadership, performance appraisal training courses should be considered a prerequisite for head nurses to occupy their position.

3. Continuous development for staff nurses relating to nursing processes, documentation principles and updated skills is necessary.

4. Further researches: replication of the research on a large probability sample is recommended to achieve more generalization.

5. Further researches are needed in areas of head nurses' transformational leadership and its effect on staff nurses' job performance and productivity.

\section{Acknowledgements}

The researchers would like to express gratitude and appreciations to (103) head nurses, their assistants and (138) staff nurses who participated in this study for their effective cooperation.

\section{References}

[1] Abdelhafiz, I. M., Alloubani, A. M., Klaledeh, M., Mutari, N., \& Almukhtar, M., (2015): Impact of leadership styles among head nurses on level of job satisfaction among staff nurses. European Scientific Journal November: p 1857-7881.

[2] Ahmad, F., Abbas, T., Latif, S., \&Rasheed, A., (2014): impact of transformational leadership on employee motivation in telecommunication sector. Journal of Management Policies and Practices. 2 (2) pp. 11-25.

[3] Ahmad, F., Abbas, T., Latif, S., \& Abdul -Rasheed., (2014): Impact of transformational leadership on employee motivation in telecommunication Sector. Journal of Management Policies and Practices. Vol. 2 (2), pp. 11-25.

[4] Al-Hilali, M., (2013): Transformational leadership and organizational effectiveness: a predictive study at American Muslim Organizations. Doctorate thesis, University of Phoenix. ProQuest LLC.

[5] Ali, R. M., Elmolla, M. A., \& Aref, S. M., (2016): Impact of transformational leadership training Program on nurse's unit manager behavior change. Journal of Biology, Agriculture and Healthcare. 6 (2). www.iiste.org.

[6] Allen, G. P., Moore, W. M., Moser, L. R., Neill, K. K., Sambamoorthi, U., \& Bell, H. S. (2016): The role of servant leadership and transformational leadership in academic pharmacy. American Journal of Pharmaceutical Education, 80 (7) 113.

[7] Alshammari, F., (2014): Nursing leadership in the ministry of health hospitals of Saudi Arabia. Doctor of philosophy (PhD) School of Health Sciences College of Science.

[8] Avolio, B., \& Bass, B., (2004): Multifactor leadership questionnaire, manual and sampler Set. 3rd., Redwood City, CA: Mind Garden, Inc., California.

[9] Awases, M. H., Bezuidenhout, M. C., \&Roos, J. H., (2013): Factors affecting the performance of professional nurses in Namibia. Journal of the Democratic Nursing Organization of South Africa, 36 (1), 60-67.

[10] Bodla, A. M., \& Nawaz, M., (2010): Transformational leadership style and its relationship with satisfaction. Interdisciplinary Journal of Contemporary Research in Business, 1 (2).

[11] Botma, Y., Botha, H., \& Nel, M., (2011): Transformation: are nurse leaders in critical care ready? Journal of Nursing Management, 20 (7), 921-927.

[12] Brewer, C. S., Kovner, C. T., Djukie, M., Fatehi, F., Greene, W., Chaclo, T. P., \& Yant, Y., (2016): Impact of transformational leadership on nurse work outcomes. Journal of Advanced Nursing, 72 (11), 2879-2893.

[13] Cheng, C., Bartram, T., Karimi, L., \& Leggat, S., (2016): Transformational leadership and social identity as predictors of team climate, perceived quality of care, burnout and turnover intention among nurses. Person.. 45 (6), 1200-1216. 
[14] Choi, S. L., Goh, C. F., Adam, M. B., \& Tan, O. K., (2016): Transformational leadership, empowerment, and job satisfaction: The mediating role of employee empowerment. Human resources for health, 14, 73.

[15] Cobb, J. R. (2008): Registered nurse-performance evaluation. from; http/www.halogen software.com.

[16] Cummings, (2010): Leadership styles and outcome patterns for the nursing workforce and work environment: A systematic review. International Journal of Nursing Studies, 7, 363-385.

[17] David, S., Armanu, A., \& Afnan, T, E., (2017): The effects of transformational leadership personality on employee performance in Nissan Malang mediated by organizational commitment. Russian Journal of Agricultural and SocioEconomic Sciences, vol. 61 (1), P. P 207-215.

[18] Deschamps, C., Rinfret, N., Legace, M. C., \& Prive, C. (2016): Transformational leadership and change: How leaders influence their followers' motivation through organizational justice. Journal of Healthcare Management, 61 (3), 194-231.

[19] Doody, O., \& Doody, C. (2012): Transformational leadership in nursing practice. British Journal of Nursing, 21 (20), 12121218.

[20] Ebrahimi, M., \& Khodaverdi, Y., (2015): Investigating the relation between transformational leadership and work interaction (work engagement) among employees of Tejarat Bank and National Bank. Sci. Int. (Lahore), 27 (3); p 27952802.

[21] El-Ghabor, G. M. (2014): The effect of work stress management training for head nurses on their job performance. Unpublished Doctorate Thesis. Port Said Faculty of Nursing, Port Said University, Egypt.

[22] Ferguson, S. L., (2015): Transformational nurse leaders key to strengthening health systems worldwide. Journal of Nursing Administration, 45, 351-353.

[23] Fisher, S. A., (2016): Transformational leadership in nursing: A concept analysis. Journal of Advanced Nursing, 72 (11), 2644-2653.

[24] Gilleta, G., Fouquereaua E, Coillota H, Bonnetainb F,\& Duponta S, (2017): Ethical leadership, professional caregivers' well-being, and patients' perceptions of quality of care in oncology. European Journal of Oncology Nursing.

[25] Giltinane, C. L., (2013): Leadership styles and theories. Nursing Standard, 27 (41), 35-39.

[26] Hayati, (2014): The relationship between transformational leadership and work engagement in governmental hospitals nurses: survey study.

[27] Higgins, E. A., (2015): The influence of nurse manager transformational leadership on nurse and patient outcomes: Mediating effects of supportive practice environments, organizational citizenship behaviors, patient safety culture and nurse job satisfaction. ProQuest published doctoral dissertation,. London, Ontario, Canada: Western University.

[28] Kotur, B., \& Anbazhagan, S., (2014): Education and workexperience - influence on the performance. IOSR Journal of Business and Management. Volume 16 (5). III, PP 104-110.

[29] Lavoie-Tremblay, M., Fernet, C., Lavigne, G. L.,\& Austin, S.,
(2016): Transformational and abusive leadership practices: impacts on novice nurses, quality of care and intention to leave. J. Adv. Nurs. 72 (3), 582-592.

[30] Lievens, I., \& Vlerick, P., (2014): Transformational leadership and safety performance among nurses: The mediating role of knowledge-related job characteristics. Journal of Advanced Nursing, 70 (3), 651-661.

[31] Luu, Nguyen, (2012): Training management skills for firstline managers. Bachelor's Thesis degree program in business management.

[32] Marshall, E. S., (2011): Transformational leadership in nursing. New York: Springer.

[33] Martin, J., (2015): Transformational and transactional leadership: An exploration of gender, experience, and institutional type. Libraries and the Academy, 15 (2), 331351 .

[34] Martin, J., McCormack, B., Fitzsimons, D., \& Spirig, R., (2012): Evaluation of a clinical leadership programme for nurse leaders. Journal of Nursing Management, 20, 72-80.

[35] Maryniak, K. D., (2013): Development of training for frontline nurse leaders. Journal for Nurses in Professional Development, 29 (1), 16-18.

[36] Melvyn, R. W., Hamstra., Nico, W.,\& Van Yperen., (2013): Transformational and transactional leadership and followers' achievement goals. J Bus Psychol. 29, PP 413-425.

[37] Millett, C. M., Millett, C. M., \& Kevelson, M. J. C., (2015): A study of the influence of the new careers in nursing program on the culture of participating schools of nursing. ETS Research Report Series, 2015 (2), 39.

[38] Moussa, M., Aboshaiqah, A., \& Alotaibi, A., (2016): Effect of nurse's supervisor's leadership style on nurse's job satisfaction. Swift Journal of Nursing and Midwifery. 2 (2); March: p. 18-25.

[39] Ng, T. W. H., \& Feldman, D. C., (2015): Ethical leadership: Meta-analytic evidence of criterion-related and incremental validity. Journal of Applied Psychology, 100 (3), 948-965.

[40] Regan S., Laschinger H. K. \& Wong C. A., (2016): The influence of empowerment, authentic leadership, and professional practice environments on nurses' perceived inter professional collaboration. Journal of Nursing Management. 24, E54-E61.

[41] Sadeghi, A., Akmaliah, Z., Pihie, L., (2012): Transformational Leadership and its predictive effects on leadership effectiveness. International Journal of Business and Social Science Vol. 3 (7).

[42] Safaria, T., Othman, A.,\& Abdul-Wahab, M. N., (2011): The role of leadership practices on job stress among Malay academic staff, structural equation modeling analysis. Journal of International Education Studies, 4 (1): 313-315\&90.

[43] Salanova, M., Lorente, L., Chambel, M., \& Martínez, I., (2011): Linking transformational leadership to nurses' extrarole performance: the mediating role of self-efficacy and work engagement. Journal of Advanced Nursing, 67 (10), 22562266 .

[44] Smith, P. O., (2015): Leadership in academic health centers: Transactional and transformational leadership. Journal of Clinical Psychology in Medical Settings, 22 (4), 228-231. 
[45] Sulieman, I., Mohammad, S., AL-Zeaud, H., Ayat, M., \& Batayneh, E., (2011): The relationship between transformational leadership and employees' satisfaction at Jordanian private hospitals. BEH, 5 (2).

[46] Swati, M.,\& Rajib, L, D., (2015): Transformational leadership and employee creativity: Mediating role of creative selfefficacy and moderating role of knowledge sharing", Management Decision, Vol. 53 (5), pp. 894-910.

[47] Tahir, L., Abdullah, T., Ali, F., \& Daud, K., (2014): Academics transformational leadership: an investigation of heads of department leadership behaviors in Malaysian public universities. Educational Studies, 40: (5), 473-495.

[48] Tessema, G., (2015): Assessing the relationships between transformational leadership and employees' engagement in North Gondar Zone Public preparatory school teachers, Ethiopia. J Econ Bus Manag, 2 (10B):1076-1085.

[49] To, M., Tse, H., \& Ashkanasy, N., (2015): A multilevel model of transformational leadership, affect, and creative process behavior in work teams. The Leadership Quarterly, 26, 543556.
[50] Vinkenburg, C. J., VanEngen, M. L., Eagly, A. H., \& Johannesen-Schmidt, M. C., (2011): An exploration of stereotypical beliefs about leadership styles: Is transformational leadership a route to women's promotion? The Leadership Quarterly, 22 (1), 10-21.

[51] Warrilow, S., (2012): Transformational leadership theory - The 4 key components in leading change \& managing change. http://EzineArticles.com/?expert=Stephen_Warrilow.

[52] Welton, J., Harper, E., (2016): Measuring nursing care value. Nurs. Econ. 34 (1), 7-14 (https://www.nursingeconomics.net/ce/2018/article340107.pdf).

[53] Wilkes, L., Cross, W., Jackson, D., \& Daly, J., (2015): A repertoire of leadership attributes: An international study of deans of nursing. Journal of Nursing Management, 23 (279288).

[54] Wilson, L. A., Crooks, E. A., Day, S. W., \& Dawson, M. A., (2014): Global perspectives on nursing leadership: Lessons learned from an international nursing and health care leadership development program. Journal of Nursing Education and Practice, 4 (2), 140. 